\title{
INTERPRETANDO INTERAÇÃO ESPACIAL FIXOS E FLUXOS, PEREGRINAÇÃO, MIGRAÇÃ̃ E RITUAL NA FOLIA DE REIS
}

Tito Oliveira Coelho (UFG)

$O$ artigo tem como objetivo investigar a mobilidade de pessoas, coisas, informações e outros fixos e fluxos (SANTOS, 1996a), fenômenos que, em interação, possibilitam compreender como o conjunto dos homens se movimenta, circula e, assim, forma uma determinada realidade geográfica. Apresenta, também, a viagem dos Três Reis Magos do Oriente à procura do Menino Jesus, como exemplo de interação espacial, tomando como categorias de análise fixos e fluxos, migração, mobilidade, deslocamento e peregrinação. Ao final, é feito breve relato sobre o giro sazonal da folia de Seu M., na região leste de Goiânia, para ilustrar essa compreensão.

\section{FOLIA DE REIS, INTERAÇÃO ESPACIAL.}




\section{INTRODUÇÃO}

Inúmeros fenômenos migratórios e suas mais diversificadas causas servem para explicitar as interações espaciais. Alguns desses casos são as manifestações promovidas pelas romarias, festa de São João, folias de reis e outros folguedos, principalmente no interior e em áreas rurais do país, onde se cultiva a fé religiosa. Trata-se, portanto, de tema importante para o campo de conhecimento da geografia humana (ULLMAN, 1974), porque revela, além de um dos modos como as pessoas se movimentam no espaço, a cultura de um povo, que é passada de geração a geração.

Esse cenário apresenta lugares (cidades, estradas, pernoites, lugares sagrados etc.); pessoas (peregrinos, comerciantes, romeiros, festeiros, devotos, foliões, comitivas, sacerdotes, leigos do padroado brasileiro...); objetos (suprimentos, aprovisionamentos, utensílios, indumentárias...); informações (profecias, histórias, mitos, crenças...) e outros elementos, que constituem os fixos e fluxos representativos das interações espaciais. Isso é reproduzido em momentos ritualísticos durante a peregrinação em romarias, nos giros de folias do divino Pai Eterno, do divino Espírito Santo, de reis, de São Benedito, São João, nas congadas, marujadas, entre outros. Desse modo, esses ritos acabam por expressar, também, uma realidade geográfica, ou seja, uma interação espacial promovida por manifestações religiosas: as festas de santos.

No tocante à tradição de cultuar os três reis santos, em visita à Sagrada Família, as companhias de santos reis chamam atenção por promover os giros sazonais, de 25 de dezembro a 6 de janeiro, quando se celebra a epifania do Senhor; mas, também, ao longo de todo o ano, quando devotos convidam os foliões para ajudar a "pagar o voto", isto é, "cumprir o prometido" (CÉSAR, 1975, p. 138). A formação e organização dessas companhias seguem estrutura semelhante à de outros grupos de folia brasileira. Por essa razão, neste estudo, é tomada como universo representativo das manifestações religiosas que provocam as interações espaciais.

Sendo assim, é necessário explicar os conceitos que norteiam a investigação, a análise e a estrutura deste trabalho, que foi organizado em quatro tópicos, propondo discutir assuntos relevantes ao entendimento do tema em pauta.

No primeiro, Interações espaciais na geografia, esclarece-se brevemente o conceito de interação espacial, tão importante para o estudo da geografia humana.

No segundo, Relações universais, fixos e fluxos como interações espaciais, explica-se a concepção das categorias de análise descritas nessa parte.

No terceiro, Migrações, peregrinações, deslocamentos, movimentos e mobilizações como elementos de interação espacial, faz-se uma síntese dessas categorias para melhor compreendê-las no processo de interpretação e/ou análise desta pesquisa.

No quarto, A peregrinação dos três reis magos e a interação espacial promovida pela Cia. de Reis Jardim das Aroeiras, apresentam-se sucintamente os rituais dos giros da companhia de reis de Seu M., como forma de exemplificar os elementos que constituem os fixos e fluxos formadores dessa realidade geográfica. Faz parte deste trabalho a análi- 
se da peregrinação sazonal e eventual da folia de reis, com o intuito de demonstrar a movimentação de determinado número de pessoas em interação espacial e em um grupo de cultura tradicional.

Nas Considerações finais elabora-se breve diagnóstico do presente, tentando colaborar com interessados que estejam buscando uma (re)leitura dos estudos sobre o tema aqui proposto.

\section{INTERAÇÕES ESPACIAIS NA GEOGRAFIA}

O trabalho de Ullman sugere sistema baseado em medidas quantitativas da mercadoria e fluxos, segundo a complexidade e o tipo das interações observadas. As variáveis básicas da interação espacial são a complementaridade, a oportunidade interveniente e a distância. As interações espaciais são influenciadas pela distância que pode aumentar o custo da transferência e o tempo de deslocamento. A distância pode declinar as interações espaciais (CORRÊA, 1997, p. 300). Assim, padrões culturais específicos podem dar origem a interações espaciais reguladas por visões particulares da distância, estabelecendo-se graus distintos de mobilidade. "Um fator final necessitado em um sistema de interação é a distância, medida em verdadeiros termos de tempo e preço" (ULLMAN, 1974, p. 33). Ao discorrer sobre distância, Rémy e Voyé (1994, p. 18) explicam que "o espaço é um modo de composição de mobilidades e de temporalidades várias, investe no domínio dos possíveis, partindo da hipótese segundo a qual a distância dificulta o contato".

Segundo Corrêa (1997, p. 302), na atualidade, "é possível articular toda a superfície do planeta Terra de forma mais efetiva com base nas áreas e centros urbanos". A oportunidade interveniente mostra-se como variável que pode agilizar e desembaraçar a articulação de alternativas ao se deparar com imprevistos e na formulação de novas ideias. As modificações ocorridas nessa movimentação social, que envolve economia de pequena escala, mostram-se com imbricações nos modelos de interação espacial. Para o autor "As interações espaciais constituem um amplo e complexo conjunto de deslocamentos de pessoas, mercadorias, capital e informação sobre o espaço geográfico" (CORRÊA, 1997, p. 279). A intensidade varia segundo a frequência, a distância e a direção dos fluxos. Existe interação espacial social e cultural em movimento, ou seja, os pontos ou nós da cultura em suas relações com suas áreas e adjacências, das áreas com suas hinterlândias (p. 298). Pela rede geográfica é que estão distribuídos os fixos interligados por fluxos de pessoas, informações, cargas e outros.

A partir dessas considerações, podem-se relacionar as interações espaciais aos fixos e fluxos, às migrações e aos movimentos ritualizados, como é o caso dos contidos em uma folia de reis. Por meio desses elementos, podemos analisar as vias e os pontos como estrutura para o movimento de pessoas e coisas; os motivos pelos quais os homens migram; e como se dão os movimentos durante os rituais cantados em diversos momentos da mobilização dos foliões e devotos. 


\section{RELAÇÕES UNIVERSAIS, FIXOS E FLUXOS COMO INTERAÇÕES ESPACIAIS}

Ao explicar a mundialização, Santos (1996a) considerou que o planeta é um só. A internacionalização de técnicas, produção, capital, trabalho, gostos, consumo e relações sociais garante a universalidade, mas, ao mesmo tempo, permite a compreensão de cada fração de modo singular e único, em um espaço globalizado. Para o teórico, a universalidade empírica permite transcrever categorias filosóficas em linguagem geográfica: "É o caso das categorias de universalidade, particularidade e singularidade, assim como das de formas, função, processo e estrutura" (SANTOS, 1996a, p. 32). A partir disso, a geografia está apta para ir além da dialética "primitiva" das geografias clássica e atuais.

A mundialização dos lugares os torna mais singulares e específicos, ou melhor, únicos, uma vez que elementos espaciais se especializaram: os seres humanos, as instituições e o meio ambiente. Cada lugar é diferenciado dos outros, "mas também claramente ligado a todos os demais por um nexo único, dado pelas forças motrizes do modo de acumulação hegemonicamente universal" (SANTOS, 1996a, p. 34). Essas ideias demonstram que nos mais diversos lugares ocorrem interações espaciais a partir da interligação de possibilidades, sendo as variáveis comuns em todo o planeta. O homem não vive isolado, as interações espaciais fazem-no um ser mais social, embora provoquem, também, sua individualização e radicalização, como no caso dos fundamentalismos, dos guetos culturais e outros.

Ullman (1974) define o conceito de situação como efeito ou fenômeno de uma área sobre outra, como conexões que permitem circulação, interdependência e difusão. A partir disso, é possível dizer que as interações espaciais se materializam mediante fluxos entre zonas. A fluidez se dá por meio dos deslocamentos de pessoas, mercadorias, jornais, ligações telefônicas, transmissão de informações e realização de negócios (ULYSSÉA \& KUHLKAMP, 2002). Também Mello (2000) esclarece a forma como os espaços estão em interação, a partir da teoria dos fixos e fluxos de Santos (1996a, 1996b). Consoante o autor, os fixos referem-se aos instrumentos de trabalho, às forças produtivas e à massa dos homens; e os fluxos, ao movimento e à circulação, que explicam os fenômenos da distribuição e do consumo: "Fixos e fluxos interagem e se alteram mutuamente" (SANTOS, 1996a, p. 77-78). Em outra versão, salienta que fixos e fluxos interagem e expressam a realidade geográfica atual: "Fixos e fluxos juntos, interagindo, expressam a realidade geográfica e é desse modo que conjuntamente aparecem como um objeto possível para a geografia" (SANTOS, 1996b, p. 50).

As mudanças sucessivas e alucinantes dos eventos, que se dão de forma vertiginosa, rompem com a convivência longa, com os mesmos objetos, trajetos e imagens; o repouso cede ao movimento, e o tempo lento, ao veloz: "Os homens mudam de lugar, como turistas ou como imigrantes. Mas também os produtos, as mercadorias, as imagens, as ideias. Tudo voa" (SANTOS, 1996b, p. 262). 
Ao estudar as interações espaciais em Foz do Iguaçu e na Ciudad del Este, Ribeiro (2001, p. 20) percebeu "a produção da fluidez espacial" através da ação do sistema de produção, da intervenção "estatal" e dos sistemas técnicos na formação da rede de relações de indivíduos, mercadorias e informações. Até a contemporaneidade, a rede de circulação e a rede de comunicação eram um só elemento ou quase um. No entanto, a tecnologia moderna as dissociou. A informação "andava" mais ou menos no ritmo das pessoas e dos bens até o século XIX, quando as distâncias comunicacionais foram praticamente abolidas, "na medida em que a transferência da informação de um ponto a outro do mundo pode ser quase imediata" (RAFFESTIN, 1993, p. 201). As distâncias temporais da circulação foram reduzidas, e a especialização das redes de circulação e comunicação as distinguiu a ponto de não se confundirem mais.

Ao comentar a metodologia para o transporte em geografia, Rodrique (2009) apontou modos de estimar "os fluxos entre localidades, uma vez que estes fluxos, conhecidos como interações espaciais, permitem avaliar a demanda (existentes ou potenciais) de serviços de transporte", sendo que o movimento de pessoas, mercadorias e informação se dá entre uma origem e um destino. Nesse caso, o transporte se dá através da procura e oferta, retratando uma relação expressa entre um lugar e outro no espaço geográfico. Para o autor, interação espacial abrange grande variedade de movimentos em que as atividades econômicas geram ofertas e atraem procura - "fluxos".

\section{MIGRAÇÕES, PEREGRINAÇÕES, DESLOCAMENTOS, MOVIMENTOS E MOBILIZAÇÕES COMO ELEMENTOS DE INTERAÇÃO ESPACIAL}

As pessoas migram por diversos motivos: para trabalhar, comercializar, consumir, visitar, estudar em escolas formais, frequentar o lugar de culto religioso, divertir-se e outros (CORRÊA, 1997). O fenômeno migratório é muito complexo e sujeito a variadas formas de olhar, a vários ângulos de análise. Mello (2000) considera que o homem percorre espaços e lugares de forma espontânea ou contingencial, na imensidão do espaço ou no recolhimento. De acordo com suas considerações, podemos migrar por meio do pensamento, do caminhar, em veículos simples ou sofisticados; as migrações não são apenas de um país para outro, entre regiões e de forma definitiva. A esse respeito Corrêa (1997, p. 279) esclarece que:

As migrações em suas diversas formas (definitivas, sazonais, pendulares etc.), as exportações e importações entre países, a circulação de mercadorias entre fábricas e lojas, o deslocamento de consumidores aos centros de compras, a visita a parentes e amigos, a ida ao culto religioso, praia ou cinema, o fluir de informações destinadas ao consumo de massa ou entre unidades de uma mesma empresa são, entre tantos outros, exemplos correntes de interações espaciais em que, de uma forma ou de outra, estamos todos envolvidos.

Por isso, existem movimentos migratórios rotineiros e episódicos, e que merecem conceituações, ao longo da evolução do pensamento geográfico. Para Mello (2000), as in- 
terações no espaço são de infinita variedade: "Na imensidão ou no recolhimento, o ser humano percorre espaços e lugares, espontânea ou contingencialmente" (MELLO, 2000, p. 87), migrando através do pensamento, caminhando, em veículos simples ou sofisticados. Segundo o teórico acima, migrar é passar "de um país para outro, ou entre regiões", ou seja, é designar deslocamentos definitivos, rotineiros e episódicos.

Considerando homem, tempo e espaço, Seamon (1980) criou o conceito de balé do lugar, partindo da noção de corpo-sujeito que, ao absorver as operações básicas de uma atividade, pode variar seu comportamento de forma mais criativa. A partir disso, o homem ganha a liberdade de se deslocar no espaço e, ao se mover em maiores ou menores percursos, promove a interação espacial: "O movimento, analisado fenomenologicamente, indica que o corpo é inteligente ativo e, através desta atividade de forma eficiente transforma as necessidades de uma pessoa em comportamentos" (SEAMON, 1980, p. 156-157).

Sem o corpo-sujeito, as pessoas teriam que planejar cada movimento, como mover a mão e dar um passo, ainda que recorrente. Ao esclarecer o conceito de corpo-sujeito, em Seamon, Pereira (2006, p. 19) o considerou "a capacidade cognitiva a qual permite que os gestos e movimentos corporais aprendidos no passado sejam lembrados imediatamente no futuro"; o corpo inteligente transforma comportamentos em "vida cotidiana".

Ao descrever esse conceito, Mello aponta os movimentos do homem proporcionados pelo balé do corpo, justificando a mobilidade espacial em direção ao lugar de trabalho e outros: "o balé do corpo e as rotinas (...) [espaçotemporais] compõem o balé do lugar. Por balé do corpo, que pode ser o ato de lavar louças, dirigir um carro, são entendidos os gestos, passos, itinerários e movimentos" (MELLO, 2000, p. 89).

No tocante ao conceito de mobilidade como expressão das organizações sociais, Becker (1997) analisa o deslocamento de populações de forma variada, envolvendo escalas espaciais diferenciadas, complexas e crescentes. Segundo a autora, suas imbricações conjunturais e relação de trabalho, os fluxos, se movimentam pelo espaço por motivos de conquista de território, fuga, novas oportunidades ou em busca de alimentos. "Desde as invasões dos povos bárbaros asiáticos até os migrantes dos novos tempos, grupos populacionais põem-se em movimento" (BECKER, 1997, p. 319), cujos interesses são a hegemonia, territórios, fuga e repressões ou simplesmente subsistência.

A sobrevivência acontece através da circulação dos homens que se comunicam ao se mover no espaço. De acordo com Raffestin (1993, p. 200), a "circulação e a comunicação" são complementares no que se refere à dominação da superfície da Terra. Em todo processo de transporte existe simultaneamente circulação e comunicação. Tanto pessoas como bens em circulação portam informações, promovendo a comunicação de alguma coisa; por sua vez, a informação comunicada é, também, um bem em circulação. A circulação e a comunicação são elementos de interação espacial por ser processos de transferência que não se excluem. A circulação é tudo aquilo que é mobilizável pelos fixos, ou seja, pelas vias de acesso. 
Ao abordar a questão da mobilidade e da migração, Trewartha (1974) considerou o homem uma criatura móvel, associada de uma mescla racial, linguística e nacional da terra. A mobilidade cresceu com o avanço econômico e tecnológico, tornando os meios de transportes e de comunicação mais eficientes. Conforme o autor, "A mobilidade sempre foi uma característica básica da população em todos os estágios de sua evolução" (TREWARTHA, 1974, p. 165) e tem aumentado com o avanço tecnológico que expandiu a eficiência dos transportes e da comunicação.

Elizaga (1970, p. 15) constatou que "as correntes migratórias dominantes se produzem tanto em comunidades (cidades, povoados, zonas rurais, regionais) com níveis de vida relativamente baixos, quanto em comunidades com níveis mais altos". Nesses pressupostos, o papel das migrações interiores seria ajustar a distribuição espacial da população às oportunidades econômicas ou pelo menos aliviar disparidades regionais. Os componentes do nível de vida são: as facilidades ao acesso escolar, aos cuidados médicos, às condições de trabalho e a outros serviços sociais. Nesse sentido, as grandes cidades latino-americanas oferecem condições nitidamente superiores às demais, pois o "desenvolvimento" econômico alcançado beneficia a capital por sua posição política e social privilegiada. Esses elementos naturais são forças de repulsão e, ao mesmo tempo, de atração, uma vez que a ação combinada destes fenômenos determina a direção e a intensidade da migração efetiva entre dois lugares.

Ao avaliar os saldos migratórios internos na Colômbia, Fornaguera (1969, p. 24) considerou que o "processo de urbanização" é parcialmente o resultado de seu crescimento demográfico, associado mais diretamente com as migrações internas. Esses argumentos demonstram a "força" do processo de migração interna evidente nas cidades, cujo fluxo tem origem nas áreas rurais, impulsionado pela crise do sistema econômico e social. Isso ocasionou a migração das famílias de cultura tradicional. Assim, observa Yap (1980, p. 794), "haverá incentivo ao deslocamento na medida em que o salário urbano esperado pelo trabalhador não qualificado for superior ao salário agrícola".

Santos e Silveira (2001, p. 167), propondo uma geografia do movimento, destacaram a produção do meio técnico-científico-informacional como motor dos círculos de cooperação que se instalam com maior complexidade em escala geográfica mais ampla: "Os fluxos daí decorrentes são mais intensos, mais extensos e mais seletivos." A seleção migratória explica que alguns indivíduos se deslocam, e outros permanecem onde estão, segundo características biológicas e culturais do povo, determinando que alguns grupos tendem mais à migração do que outros. Se considerarmos o termo migração movimento de uma extensão que provoca a mudança da residência permanente, excluímos outros tipos de mobilidades que geram a interação espacial, tal como "as viagens diárias periféricas, as deslocações sazonais de trabalhadores migratórios, o movimento temporário e irregular dos turistas e o caminhar errático dos pastores nômades" (TREWARTHA, 1974, p. 166). Por esse motivo, define-se migração de forma mais ampla, incluindo a mobilidade populacional no espaço com suas especificidades e particularidades em cada país, região, localidades e lugares. 
Nos tempos antigos, as interações no espaço ocorreram em consequência de invasões territoriais e migrações entre nações e regiões; e, em nossos tempos, devido à busca de hegemonia, de novos territórios, para fugir de perseguições étnicas, políticas, religiosas e outros tipos de repressões. Nos tempos modernos, há grande migração em busca de terras, novas oportunidades, mercados, trabalho, atividades que assegurem a subsistência e também visando aos lugares de culto e devoção.

Na relação entre sujeitos, há observações e comentários personalizados dos indivíduos, no sentido de vigilância recíproca benevolente ou malevolente, ao praticar a solidariedade, confiança e a simpatia, de acordo com a qualidade da relação interpessoal. Em sua abordarem da interação e do controle no sistema social, Rémy e Voyé (1994, p. 28) registram: "Se se entender por interações as interdependências que resultam de atividades coletivas, o sistema social será a organização destas com referência a prioridades que definem o lugar do poder e a sua capacidade de controlo." Segundo Raffestin (1993, p. 88), a mobilidade é de difícil controle pelas "organizações interessadas em modificar" a repartição e a distribuição dos homens no espaço. É mais fácil analisar as relações de força que provocam a mobilidade do que a natureza que a determina.

Há casos em que a migração pode ocorrer de forma autônoma, com a decisão própria do migrante, ou de forma coercitiva. No caso da migração esporádica para os lugares sagrados, como é o caso das romarias e folguedos, pode-se observar a necessidade de se interagir com o outro, deixando o labor para se movimentar de forma livre em relação às relações patronais. $O$ deslocamento para os lugares de culto pode ser visto como imposição; mas, também, desejo de comungar com a divindade, sentir-se útil, obter ânimo para retornar ao cotidiano ou mesmo exercer alguma forma de poder.

Uma questão relevante à análise geográfica é a correlação existente entre migração e peregrinação. Migrar segundo Cunha (2007, p. 520) tem o significado de "mudar, passar de um lugar para outro, ir-se embora, sair"; já o termo peregrinar tem o sentido de "viajar ou andar por terras distantes" (p. 595) em forma de romaria e devoção pelos lugares santos. Segundo Arnt (2006, p. 21), o indivíduo é romeiro quando se desloca, "por disposição própria e sem esperar recompensas materiais ou espirituais"; é peregrino quando "visita lugares sagrados para cumprir promessas ou pedidos anteriores feitos a divindades ou a espíritos bem-aventurados"; e é penitente quando "se desloca a locais sagrados, com intenção de redimir-se de seus pecados e culpas" espontaneamente ou por conselho de alguém. $O$ termo está relacionado "com o estrangeiro, aquele que não pertence ao lugar por onde passa, ocasionando o encontro com o 'outro' capaz de produzir estranhamento" (CALVELLI, 2006, p. 23), como é o caso dos reis magos.

Dessa forma, cabe afirmar que a festa religiosa é elemento que promove fortes interações espaciais, por gerar mobilidade em direção ao espaço de se alegrar, satisfazer a alma, fazer amizade e se ver sem compromisso laboral. Ao analisar a festa, Teixeira $(1988$, p. 23) aponta que "tudo isso é expresso numa síntese perfeita, por coisa boa". Nas festas, procura-se o desfrute da vida, longe das privações, e, por isso, elas possuem grande poder de mobilização. Toda a população local participa ou é afetada pela festa. Ela 
proporciona, destarte, mobilidade emotiva, íntima, de interesses comuns, tornados rituais locais.

\section{A PEREGRINAÇÃO DOS TRÊS REIS MAGOS E A INTERAÇÃO ESPACIAL PROMOVIDA PELA COMPANHIA DE REIS JARDIM DAS AROEIRAS}

Se analisarmos o espaço de festas sacroprofanas, perceberemos os elementos de interação espacial, sabendo que o sagrado não se mistura ao profano, mas também que eles não se excluem. Segundo Eliade (2001, p. 17) "a primeira definição que se pode dar ao sagrado é que ele se opõe ao profano". Na perspectiva do autor, é possível conhecer o sagrado porque se "manifesta", se mostra diferente do profano, em forma de hierofania: algo de sagrado se revela. Pode-se dizer, então, que são manifestações das realidades sagradas em objetos, pedra, árvore (hierofania elementar) ou a encarnação de "Deus em Jesus Cristo" (hierofania suprema), conhecida como epifania do Senhor. Também Rosendahl (1996, p.27) explicita que "o ser humano, ao aceitar a hierofania, experimenta um sentimento religioso em relação ao objeto sagrado". Esses elementos provocam uma forma de migração: a peregrinação aos lugares sagrados, que sempre têm também uma festa considerada profana, e tudo faz parte do ritual, da festa.

Ao perceber a complexidade do fato religioso como elemento histórico, Eliade (1996, p. 27) afirma: “A mais nobre mensagem religiosa, a mais universal experiência mística, o mais comum dos comportamentos humanos - como, por exemplo, o temor religioso, o rito, a prece - singularizam-se e delimitam-se à medida que se manifestam." Segundo Durkheim (2000), o conceito de religião é constatado pela espiritualidade de toda espécie e de toda ordem, com que os povos atribuíram sentido à natureza. Logo, são objetos de ritos ou de um culto regular. Os ritos e rituais são realizados "por" devoção a um ser espiritual. De acordo com o autor, "as almas dos mortos, os espíritos de toda espécie e de toda ordem" (DURKHEIM, 2000, p. 11) são objetos de ritos e cultos. A partir dessa constatação, compreendemos que os rituais contidos no giro de uma folia de reis são cultos aos seres espirituais superiores (os que estão na guia, simbolizados pela bandeira, e nos presépios, a saber, Jesus, Maria, José e os reis Melchior, Gaspar e Baltazar), a Santíssima Trindade, os anjos, os familiares falecidos dos devotos e outros.

Crenças religiosas são "forças" que exprimem a natureza dos elementos sagrados e suas relações entre si ou com os considerados profanos; mas "os ritos são regras de conduta que prescrevem como o homem deve comportar-se com as coisas sagradas (DURKHEIM, 2000, p. 24). A folia de reis é dotada de regras de condutas reivindicando uma série de comportamentos durante todo processo de deslocamento. Com base nos estudos rituais e nas emoções das interações espaciais, contextualizando festas populares de romaria e folguedos, Maia (2010, p. 87) observou a compreensão de Durkheim em relação à "natureza da experiência espacial (e temporal), enquanto apresenta uma concepção paradoxal de ritos" e apontou duas categorias fundamentais dos fenômenos 
religiosos: crenças e ritos. Mesmo discutindo a relevância da distinção das crenças e ritos, constatou que o autor foi contraditório:

Durkheim, priorizando uma abordagem funcionalista da relação rito/crença, criou um problema insolúvel para si próprio - pois, conforme foi citado anteriormente, os ritos são explicados pela crença -, quando ele mesmo, em passagens de sua obra, inverte tal lógica de raciocínio (MAIA, 2010, p. 88).

Durkheim (2000) considerou, ainda, as crenças opiniões, representações e pensamento; e os ritos, modos de ação determinados, enfim, o movimento do pensamento. Afirmou a crença como definição primeira, e o rito servindo apenas para manter a vitalidade daquela, para que as memórias não se apaguem. Então "O funcionalismo de Durkheim influenciou interpretações do fenômeno religioso em que definições esquemáticas de espaço sagrado e profano partem das crenças, argumento que nem mesmo Durkheim, conforme dissemos, consegue sustentar em seu estudo" (MAIA, 2010, p. 89). Apesar da contradição, a teoria de Durkheim serve para orientar a questão do movimento proporcionado pelos rituais. São elementos de suma importância para pensar os deslocamentos ocasionados pelo processo do giro ou jornada da folia estudada.

Fundamentado nas pesquisas de ritos nas folias de Reis, Porto (1982, p. 28) registra: "O homem sempre cria ritos. As diversas manifestações folclóricas têm os seus ritos. As folias de reis também têm os seus." O espírito religioso anima e motiva o deslocamento dos foliões, pois "o espírito de fé e a disposição para o sacrifício animam todas as atividades de um folião". O autor classificou "os ritos de uma companhia de reis em cinco grupos", sendo eles a chegada a uma casa, a louvação, o encontro de folias, o encontro com um pobre ou visita a uma família pobre e a festa de encerramento.

Se interações espaciais são conexões entre lugares, por meio da transferência e deslocamento de coisas, pessoas e informação, podemos analisar a forma como isso ocorre nos rituais trovados das folias de reis. Maia (2010) esclarece que, nos rituais, as pessoas em deslocamento ritualístico são copresenças, ou modo de ser-no-mundo, ao reconhecer também seu ser-no-mundo nos outros. Observa-se que, no processo ritual, há passagem do individual ao coletivo, e o participante se vê na qualidade de ser-com juntamente com os demais, distinguindo-os dos estranhos. Então, há diferenciações entre indivíduos, não havendo só harmonia entre os partícipes no modo de ser no ritual; naturalmente, vão surgindo hierarquias, negociações, resistências às ordens, conflitos e tensões.

As interações espaciais podem ser analisadas por meio de fé, crença, devoção aos santos reis e movimentos promovidos pelos rituais cantados da folia. Aí, podem ser observados os direcionamentos e os posicionamentos espaciais proporcionados pelo deslocamento da bandeira, pelos versos trovados e por outros movimentos pertinentes. Eles se referem à direção de saída e chegada da bandeira, aos movimentos para não cruzar a bandeira (por acreditar que, se isso ocorrer, um festeiro ou um folião pode falecer), à saída da bandeira, ao almoço e ao pouso, ao agradecimento de mesa e outros. As interações espaciais se mostram, igualmente, na cultura de dar, receber e retribuir, ou seja, di- 
reitos, obrigações de um doador para um donatário, em que as ações se movimentam de forma material e espiritual.

Buscando ser conciso, podemos dizer que a peregrinação dos Três Reis Magos do Oriente promoveu uma interação espacial ao sair de suas terras, passar pelo palácio de Herodes e seguir a caminho de Belém, à procura do Menino Jesus. Consideramos que as vias de acesso pelo deserto, os lugares em que pediram alimento, pouso e descanso foram os pontos fixos principais da jornada. O fluxo consistiu dos três magos e suas comitivas em peregrinação, deslocamento e movimento orientados por uma estrela. Desde a época do nascimento, Jesus foi "um ser humano da geografia" (BRANDÃo, 1989, p. 27), proporcionando transferência de pessoas entre os lugares. E a jornada ou o giro de folias de reis dos nossos dias é a reprodução simbólica dessa interação espacial dos tempos do nascimento do Messias.

Um exemplo é a Companhia de Reis Jardim das Aroeiras, composta por cerca de 45 foliões entre três e 90 anos. Seu M., o capitão, é o responsável pelo grupo de embaixadores, coral de sete vozes e tocadores de violão, viola, cavaquinho, sanfona, pandeiro, maracá e caixa. Compõe a companhia um grupo de catira que se apresenta mediante solicitação dos devotos. O giro sazonal tem duração de 11 dias, mas é antecedido de minuciosa preparação, que se constitui do tempo de espera, da marcação dos pousos e almoços, de reuniões na casa do capitão e do festeiro, e dos agendamentos de locomoção. O ritual é composto pela "benzeção" da companhia pelo capitão, suas recomendações, advertências e exigências de conduta durante as visitas; saída da bandeira, visita às casas que aceitam receber a guia, chegada no almoço e no pouso, agradecimento de mesa, saída do almoço e pouso, canto ao falecido e de entrega do voto; a entrega da bandeira é um ritual composto de saudação do rei e da rainha, canto do nascimento, passagem da coroa e entrega com festa e despedida.

Nos 11 dias de peregrinação no giro de 2009/10 a folia de Seu M. se movimentou por 212 moradias na região leste de Goiânia. O grupo se deslocou da casa dos festeiros no Parque das Amendoeiras, peregrinando por 16 parques, bairros, setores, jardins e outras designações. Houve necessidade de locomoção de foliões em veículos de integrantes da folia e de seus parentes, para o Jardim Novo Mundo e Setor Universitário. Ressalta-se que na recolhida da folia os rituais são semelhantes aos de chegada no almoço e no pouso, mas os donos da casa (festeiros) são saudados como rei e rainha. A folia saúda os arcos e se desloca até o presépio, cumpre os rituais de saudação e vai para a mesa passar a coroa. São sorteados os festeiros novos por uma criança "inocente" cuja identidade só os palhaços podem conhecer. Faz-se toda a cantoria de passagem e uma pausa para os paIhaços simularem a procura do casal de festeiros do ano seguinte. Encontrados os novos festeiros, o palhaço faz o verso solicitando que o embaixador continue o ritual. Em seguida, os foliões seguem em direção ao presépio. Depois, o embaixador canta entregando: a bandeira, o alferes, os vigias (palhaços), os instrumentistas, o capitão, os embaixadores que giraram para os festeiros anteriores e atuais. Ao final da cantoria, é solicitado aos festeiros que virem a bandeira para pousá-la na lapinha. Nesse momento, os foliões vão 
para a mesa do jantar seguidos dos convidados. Aqui, não há a cantoria de agradecimento de mesa, pois a bandeira e os foliões já foram entregues aos festeiros, segundo informação do Seu M, capitão da Folia de Santos Reis do Jardim das Aroeiras, em Goiânia. Às vezes, pode haver catira e forró depois da comilança.

\section{CONSIDERAÇÕES FINAIS}

De acordo com as (re)leituras realizadas para este trabalho, considera-se que a tradição das manifestações religiosas no Brasil é uma representação simbólica do deslocamento de pessoas que, motivadas por fé, devoção e necessidade de peregrinar, saem de locais distantes com destino aos festejos de santos nos mais variados espaços do território brasileiro.

A folia de Seu M. em Goiânia não foge dessa representação simbólica, uma vez que esse ritual ocasiona forte interação espacial, ao provocar a migração de foliões para o Jardim das Aroeiras, onde mora; a peregrinação entre os lugares (saída, pousos, almoços e entrega) com vários deslocamentos em pequenas dimensões de tempo-espaço; o movimento de pessoas, coisas e ideias durante o giro e os rituais; e a mobilização de pessoas para que a festa aconteça. No dia da entrega, a casa do festeiro se confunde com a rua, sendo complementares.

Mediante o exposto, percebe-se, claramente, que as manifestações promovidas pelas romarias, festas religiosas e outros folguedos podem ser vistas e analisadas como um lugar de ação, interação, troca, realização e crescimento, cuja interpretação pode ir além da geografia humana. Não olvidando que, por meio das manifestações religiosas, o homem participa da sociedade, relaciona-se com outros ritos e forma o meio social do qual ele é produto.

\section{REFERÊNCIAS BIBLIOGRÁFICAS}

ARNT, Lionara. Peregrinação $X$ turismo religioso: um estudo de caso no Santuário de Azambuja - Brusque, SC. 2006. Dissertação - mestrado em Turismo e Hotelaria, Programa de Pós-Graduação em Turismo e Hotelaria, Universidade do Vale do Itajaí/Univale, Balneário Camburiú, SC, 2006. Disponível em: <https://www6.univali.br/tede/tde_ busca/arquivo.php?codArquivo=288>. Acesso em: 25 jul. 2010.

BECKER, Olga M. Schild. Mobilidade espacial da população: conceitos, tipologia, contextos. In CASTRO, Iná E. de; GOMES, Paulo C. da C; CORRÊA, Roberto L (orgs.). Explorações geográficas: percursos no fim do século. Rio de Janeiro: Bertrand Brasil, 1997, pp. 319-367.

BRANDÃO, Carlos R. A cultura na rua. Campinas: Papirus, 1989.

CALVELLI, Haudrey G. A "Santiago de Compostela" brasileira: religião, turismo e consumo na peregrinação pelo Caminho da Fé. 2006. Tese - doutorado em Ciências da Religião, Programa de Pós-Graduação em Ciências da Religião, Instituto de Ciências Humanas da Universidade de Juiz de Fora, Juiz de Fora, MG, 2006. Disponível em: <http://www. diaadiaeducacao.pr.gov.br/diaadia/diadia/arquivos/File/conteudo/artigoteses/ENSINORELIGIOSO/teses/santiagocompostelabrasileira.pdf>. Acesso em: 24 jul. 2010. 
CÉSAR, Getúlio. Crendices: suas origens e classificação. Rio de Janeiro: Apex Gráfica e Editora, 1975.

CORRÊA, Roberto L. Interações espaciais. In: CASTRO, Iná E. de; GOMES, Paulo C. da C; CORRÊA, Roberto L. (org.). Explorações geográficas. Rio de Janeiro: Bertrand Brasil, 1997, pp. 279-318.

CUNHA, Antônio G. Dicionário etimológico da língua portuguesa. Rio de Janeiro: Leixikon Editora Digital, 2007.

DAMATTA, Roberto. O que faz o Brasil, Brasil? Rio de Janeiro: Rocco, 1991.

DURKHEIM, Émile. As formas elementares da vida religiosa: o sistema totêmico na Austrália. São Paulo: Martins Fontes, 2000.

ELIADE, Mircea. Imagens e símbolos: ensaio sobre o simbolismo mágico-religioso. São Paulo: Martins Fontes, 1996.

. O sagrado e o profano: a essência das religiões. São Paulo: Martins Fontes, 2001.

ELIZAGA, Juan C. Migraciones a las áreas metropolitanas de America Latina. Santiago de Chile: Celade, 1970.

FORNAGUERA, Miguel. Evaluacion de saldos migratorios internos: ensayo de um metodo y algunos resultados de su aplicacion en Colômbia. In GUTIERREZ, Ramiro C (coord.). Migración y desarrollo urbano en Colombia. Memória Del II Seminário nacional sobre urbanizacion, s. I., 1969, pp. 24-47.

MAIA, Carlos E. S. Ritual e emoção nas interações espaciais: repensando o espaço sagrado nas festas populares de romarias e folguedos. In ROSENDAHL, Zeny (org.). Trilhas do sagrado. Rio de Janeiro: Eduerj, 2010, pp. 87-111.

MELLO, João B. F. de. Dos espaços da escuridão aos lugares de extrema luminosidade: o universo da estrela Marlene como palco e documento para a construção de conceitos geográficos. 2000. Tese - doutorado em Geografia, Programa de Pós-Graduação em Geografia, Universidade Federal do Rio de Janeiro/UFRJ, 2000.

PEREIRA, Roberta C. Comunicação e cultura popular: a trajetória dos lugares através do samba. Dissertação - mestrado em Comunicação, Universidade Estadual do Rio de Janeiro, 2006. Disponível em: <http://www.bdtd.uerj.br/tdebusca/arquivo. php?codArquivo $=661>$. Acesso em: 30 mai. 2010.

PORTO, Guilherme. As folias de reis no Sul de Minas Gerais. Rio de Janeiro: MEC-SEC/Funarte/Instituto Nacional do Folclore, 1982.

RAFFESTIN, Claude. Por uma geografia do poder. São Paulo: Ática, 1993.

RÉMY, Jean; VOYÉ, Liliane. A cidade: rumo a uma nova definição? Lisboa: Afrontamento, 1994.

RIBEIRO, Letícia P. Interações espaciais na fronteira Brasil-Paraguai: as cidades-gêmeas Foz de Iguaçu e Ciudad del Este. 2001. Dissertação - mestrado, Universidade Federal do Rio de Janeiro, 2001.

RODRIQUE, Jean-Paul. Spatial Interactions. Disponível em: <http://people.hofstra.edu/geotrans/eng/ch5en/meth5en/ch5mlen.html>. Acesso em: 24 mar. 2009.

ROSENDAHL, Zeny. Espaço e religião. Rio de Janeiro: Uerj/Nepec, 1996.

SANTOS, Milton. Metamorfoses do espaço habitado. São Paulo: Hucitec, $1996 a$.

.A natureza do espaço: técnica e tempo, razão e emoção. São Paulo: Hucitec, $1996 \mathrm{~b}$. 
SANTOS, Milton; SILVEIRA, Maria L. O Brasil: território e sociedade no início do século XXI. Rio de Janeiro: Record, 2001.

SEAMON, D. Body-subject, time-space routines, and place-ballets. In BUTTIMER, A. and SEAMON, D. The Human Experience of Space and Place. New York: St. Martin's Press, 1980, pp. 148-156.

TEIXEIRA, Sérgio A. Os recados das festas: representações e poder no Brasil. Rio de Janeiro: Funarte/Instituto Nacional do Folclore, 1988.

TREWARTHA, Glenn T. Geografia da população: padrão mundial. São Paulo: Atlas, 1974.

ULLMAN, E. L. Geography as spatial interaction. In M. ELIOT-HURST, M. E (ed.). Transportation Geography: Comments and Readings. New York: McGraw-Hill, 1974, pp. 27-40.

ULYSSÉA NETO, Ismael; KUHLKAMP, Nilo. O tratamento do espaço em modelos de interação espacial: considerações sobre a determinação das oportunidades intervenientes. Congresso Brasileiro de Cadastro Técnico Multifinalitário/Cobrac 2002, UFSC, Florianópolis, 6-10 out. 2002. Disponível em: <http://geodesia.ufsc.br/Geodesia-online/arquivo/cobrac_2002/018.HTM>. Acesso em: 30 jan. 2007.

YAP, Lorene. Internal migration and economic development in Brasil. In MOURA, Hélio A. de. Migração interna. Fortaleza: BNB/Etene, 1980, pp. 779-806.

Tito Oliveira Coelho é professor de geografia; graduado em geografia pelo IESA/UFG; especialista em história pelo FCHF/UFG; mestre em geografia pelo lesa/UFG e doutorando em geografia pelo Programa de Pós-Graduação em Geografia do Instituto de Estudos Socioambientais lesa/UFG. 